\title{
CJLT

\section{Using Tablet Computers with Elementary School Students with Special Needs: The Practices and Perceptions of Special Education Teachers and Teacher Assistants \\ Utilisation des tablettes électroniques avec des enfants d'école primaire à besoins spéciaux : pratiques et perceptions des enseignants et aides- enseignants en éducation spéciale.}

\author{
Genevieve Marie Johnson, Curtin University
}

\begin{abstract}
Twelve special education teachers and teacher assistants who have instructional experience using iPads with children with special needs completed a survey that queried their practices and perceptions. In general, teachers and assistants were extremely positive about the value of iPads for children with special needs, particularly for children with autism, attention deficits and limitations of fine motor control. Special education teachers and teacher assistants reported most frequently using iPads to promote student language and literacy skills, although mathematics learning activities were also commonly reported. Enhanced student motivation was the most frequently reported benefit of using tablet computers in school followed by instructional planning advantages. Tablet computers appear to have the potential to be an essential aspect of individual program plans. Teaching tasks might reasonably include downloading and organizing specific applications on specific children's tablets and professional development might increasingly focus of evaluation of tablet applications.
\end{abstract}

Keywords: iPad; tablet computer; special needs; special education; instructional technology

\section{Résumé}

Douze professeurs en éducation spéciale et aides-enseignants utilisant les iPads dans leur enseignement avec des enfants à besoins spéciaux ont rempli un questionnaire relatif à leurs pratiques et à leurs perceptions. En général, les enseignants et les aides-enseignants se sont révélés extrêmement positifs quant à la valeur des iPads pour les enfants à besoins spéciaux, en particulier pour les enfants avec autisme, avec un déficit d'attention et avec un contrôle limité de 
la motricité fine. Le plus souvent, les enseignants en éducation spéciale et les aides-enseignants ont indiqué avoir utilisé les iPads pour améliorer les compétences linguistiques et de littératie des élèves, bien que des activités d'apprentissage des mathématiques aient aussi été mentionnées fréquemment. Le renforcement de la motivation des élèves constituait l'avantage le plus souvent associé à l'utilisation des tablettes à l'école, suivi par des avantages liés à la planification de l'enseignement. Les tablettes pourraient devenir un élément essentiel des plans de programme individuel. Les tâches d'enseignement pourraient inclure le téléchargement et l'organisation d'applications spécifiques sur les tablettes particulières des enfants, et le perfectionnement professionnel pourrait de plus en plus être consacré à l'évaluation des applications pour tablettes.

\section{Introduction}

With respect to contemporary digital technology, a tablet refers to a single panel computer with a touch screen as the input device. "After years of limited success with tablets from a variety of vendors, in 2010, Apple's iPad created a tablet revolution as dramatic as it did with the iPhone" (Computers Desktop Encyclopaedia, 2012, paragraph 2). While tablet computers such as the iPad were not initiated as educational tools or, indeed, promoted as particularly child-friendly, the device quickly moved into schools (Grezlak, 2011; Jackson, 2011; McCrea, 2010) and emerged as a favourite childhood toy (Learmonth, 2010). In comparison to traditional computers, Harrison (2010) argued for the educational superiority of iPads because the iPad is formatted to be an ebook, has multiple mechanisms of connectivity (e.g., WiFi and 3G) and is highly portable.

As illustrated in Figure 1, tablets' mobile capability, touch screen, and intuitive operation make the devices appealing to many, and are especially valuable to children with special needs (Johnson, 2013). iPads are promoted as extremely useful for children with all sorts of special needs (Dixon, 2011) including communication disorders and autism (Valentine-Devries, 2010). "The iPad is a great alternative for children with speech challenges and motor control problems, as the iPad is easy to use with its large touch screen and swipe controls" (Tablet Computer News, 2011, paragraph 5). Recently, iPad applications have been developed to target the special learning needs of children with attention deficit disorders (Namahoe, 2012). Ellis (2011) reported a case study in which iPads were used in school by children with intellectual disabilities and in a hospital setting by children receiving medical treatment. Based on interviews with school and hospital personnel, benefits of iPads reportedly included self-directed learning, personalized learning, extension of learning, accessibility, increased engagement and enhanced social interaction. Reported challenges included administration (e.g., purchasing appropriate applications) and security (e.g., lost and stolen tablets). The State of Victoria (Australia) Department of Education and Early Childhood Development (2010) published a guide to iPad applications appropriate for use with students with special needs including: organisational apps, communication and assistive technology apps, reading apps, writing apps, math apps, art and technology apps, and music and song apps. In a very short period of time and with limited empirical evidence, tablet computers such as the iPad are increasingly perceived as essential in special education classrooms (Dunn, 2012). 


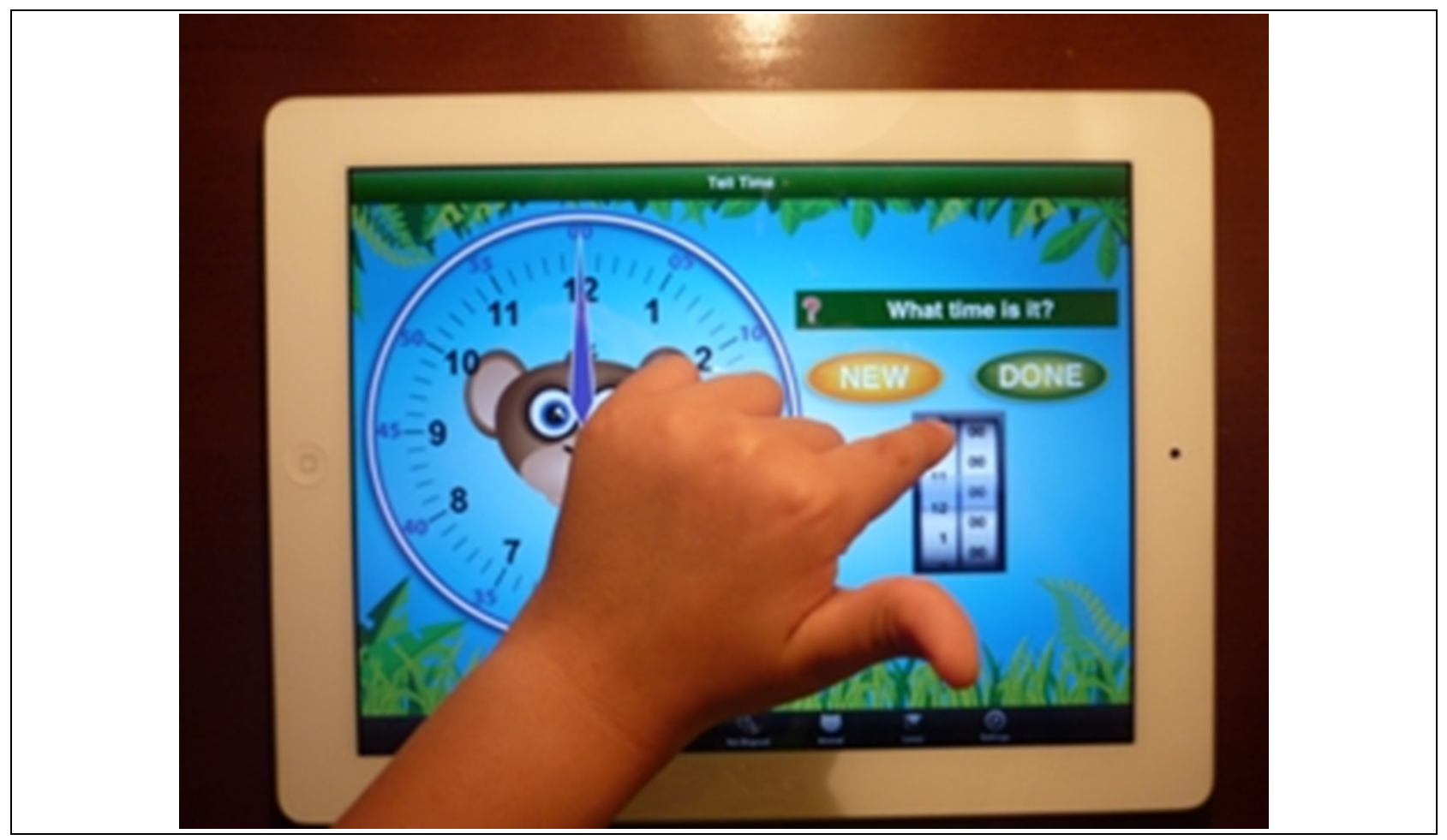

Figure 1: Tablet Computer (iPad) with Touch Screen Input

\section{Research Focus and Questions}

In relation to children with special needs and tablet computers, the swirl of anecdotal success stories and the barrage of apps geared towards these needs are not necessarily supported by sound educational research (Johnson, 2013) Since teachers increasingly use iPads to support student learning, their opinions and perceptions may contribute to improved understanding of effective applications of such technology. The current investigation sought to describe the perceptions of special education teachers and teacher assistants who have experience using iPads to meet the educational needs of elementary school children diagnosed with specific learning challenges. The current investigation attempted to address the following research questions:

1. What iPad learning activities occur in special education classrooms?

2. Which curriculum areas are targeted by iPad use for children with special needs?

3. According to teachers and assistants, are tablet computers more or less appropriate for students with different sorts of special needs?

4. What do special education teachers and teacher assistants perceive as the advantages and disadvantages of tablets for elementary school students with special learning needs? 


\section{Methods}

\section{The Context: Three Special Education Elementary School Classrooms}

For approximately eight months, special education teachers and teacher assistants in an Education Support Centre in Western Australia have been regularly using iPads with students with special learning needs (i.e., that cannot be accommodated in the context of the regular classroom). The Educational Support Centre, linked to an elementary school, provides instruction to 21 students with special learning needs. Based upon assessment and diagnosis, students typically enter the Education Support Centre at approximately 5 years of age and continue there through to Year 7 (i.e., up to 13 years of age). Students enrolled in the Education Support Centre at the time of the study included children diagnosed with intellectual disabilities, autism, visual impairment and cerebral palsy. Students in the Education Support Centre are grouped by age into three classes. Each classroom has a special education teacher and special education teacher assistants. Teachers and assistants have been encouraged to use iPads and teachers have developed educational plans for children with special needs that include the use of iPads. There are six iPads within the Education Support Centre, two allocated to each class group. Special education teachers and assistants have been in-serviced in the use of iPads for students with special needs including review and evaluation of a variety of popular applications to improve student skills in core curriculum areas (i.e., reading, writing and mathematics) as well as games, puzzles and language applications (e.g., Jungle Fractions, Jungle Times, Paint Sparkle, Doodle Buddy, 1-20 Balloons and Where Do I Go?).

\section{The Survey: Determining Instructional Practices and Perceptions}

A survey was developed specifically for this study, which queried special education teachers and teacher assistants in the Educational Support Centre who used iPads when teaching children with special needs. Survey items queried demographics (e.g., age, gender, qualifications) and personal use of digital technologies (i.e., to establish comfort with emerging technologies). Additionally, the survey included six opened-ended items such as For what sorts of activities do your students use iPads and What sorts of students appear to respond most favourably to iPads? Early in the school year, surveys and invitations to participate (as required by research ethics) were distributed to the three special education teachers and 12 special education teacher assistants employed in the Educational Support Centre.

\section{Survey Respondents: Special Education Teachers and Teacher Assistants}

Twelve of the 15 surveys were completed and returned; the survey sample included three special education teachers and nine special education teacher assistants. All those invited to complete the survey were female. The 12 respondents to the survey ranged in age from 24 to over 50 years (mean age 37 years); ranged in years working in a school from 1 to 12 (mean 5.6 years); ranged in years working with children with special needs from less than one year to 15 years (mean 5.6 years). Special education teachers' self-reported qualifications ranged from a Bachelor of Education degree to a Master of Arts degree with a Diploma of Education and a post-graduate certificate in special education. Special education teacher assistants reported a range of qualifications, most commonly, Education Assistant Certification, although one respondent reported a nursing credential and another noted that they had no postsecondary education. Five respondents indicated that they taught junior elementary (Years 1 to 3; children 5 to 9 year of 
age), four respondents indicated that they taught middle elementary (Years 4 and 5; children 9 to 11 year of age) and three respondents indicated that they taught upper elementary (Years 6 and 7; children 11 to 13 year of age). Summarized in Table 1, all respondents appeared digitally literate (e.g., most text messaged daily). Ten teachers/assistants indicated that they used iPads with their students daily, one indicated nearly every day and one indicated weekly.

Table 1: Teacher/Assistant Self-Reported Level of Use of Digital Technology

\begin{tabular}{|l|c|c|c|c|}
\hline \multirow{2}{*}{\multicolumn{1}{|c|}{ Survey Item }} & \multicolumn{4}{c|}{ Response-Option } \\
\cline { 2 - 5 } & Never & Monthly & Weekly & Daily \\
\hline How often do you use email? & 0 & 0 & 4 & 8 \\
\hline How often do you text message? & 0 & 0 & 1 & 11 \\
\hline How often do you visit websites? & 0 & 0 & 2 & 10 \\
\hline How often do you play online games? & 7 & 2 & 2 & 1 \\
\hline
\end{tabular}

\section{Data Analysis}

Responses to open-ended survey items were organized in terms of similarities or common themes and tallied. Sample size was too small (maximum $n=15$ ) to allow for any meaningful statistical analysis. In this regard, the study, although using survey data, is entirely qualitative and descriptive.

\section{Survey Results}

In many cases, special education teachers/assistants indicted more than one response to a survey item and thus tallies frequently exceeded twelve (i.e., the number of respondents). Table 2 provides a summary of teacher/assistant responses to the open-ended survey item For what sorts of activities do your students use iPads? All responses focused on the core curriculum areas of literacy and mathematics although, in some cases, prerequisite or foundational skills were the target of tablet computer use. For example, one teacher reported using the iPad for students to listen to music, which may facilitate the auditory processing of information and, ultimately, may lead to improved listening skills, essential to literacy development. Additionally, iPad use was frequently viewed as contributing to the development of fine motor skills (i.e., control of small muscles in the fingers), which is prerequisite to printing, a fundamental literacy skill. In addition to touch screen input, which involved fine motor control, children used stylus pens which were also perceived by participating special education teachers/assistants as improving finger control. As one special education teacher wrote: "Stylus pens are good for those students who are lefthanded or tend to drag their whole hand across the screen."

Two open-ended survey items queried special education teacher and teacher assistants' perception of the types of students who responded most and least favourably to using iPads in school. Six of the 12 respondents noted that all students responded favourably to the iPad as an instructional device. Written responses included: "All of our students love the opportunity to use the iPads. They feel as though they are being rewarded." With respect to those students who responded least favourably, ten of the 12 teachers/assistants indicated that they had not yet encountered a child who did not respond favourably to iPad use in school. However, special education teachers/assistants did provide additional information on students who appeared to respond most favourably to the iPad. Three respondents identified students with autism as 
responding extremely positively to the tablet computers. For example, one special education teacher assistant wrote: "All enjoy but autistic children the most by far." Two respondents identified children with fine motor limitations as responding extremely well to the tablets because with touch screen input, children did not have to control their finger muscles as precisely as, for example, when printing or typing. Two respondents expressed the perception that students with attention deficits, perhaps due to increased motivation and/or enhanced sensory input, responded very well to using a tablet in school. One teacher assistant noted, "All have a positive response -- boys a bit more than girls." Another respondent observed, "Students who need multisensory input i.e., auditory and visual cues appear to respond most favourably to the iPad." In terms of students who responded least favourably, while most teachers/assistants did not identify any type of student, two respondents mentioned children with limited intellectual ability, specifically "Down Syndrome" and those with "poor cognition."

Table 2: Teacher/Assistant Response to the Survey Item For what sorts of activities do your students use iPads?

\begin{tabular}{|c|c|}
\hline Curriculum Area/Activity Listed & Times Mentioned \\
\hline Literacy & $\mathbf{2 5}$ \\
\hline Fine motor skills prerequisite to printing & 7 \\
\hline Letter recognition and phonetics & 7 \\
\hline Speech and language production & 5 \\
\hline Listening activities & 4 \\
\hline Taking photographs & 2 \\
\hline Mathematics & $\mathbf{1 6}$ \\
\hline Number recognition & 5 \\
\hline Addition and counting & 4 \\
\hline Puzzles and patterns & 4 \\
\hline Sorting and classifying & 3 \\
\hline
\end{tabular}

Table 3 provides a summary of special education teacher and teacher assistant perceived benefits of using iPads with elementary school children with special learning needs. The most common response to the open-ended survey item focused on student motivation to use the iPad including comments centred on student engagement such as "Makes learning fun -- they think they are playing because it is a computer." Another respondent wrote, "There are many benefits as they seem a fun way for children to learn, both physically and visually stimulating and keeping the child focused for longer." Terms such as attention and concentration appeared three times in written responses, for example: "iPads can extend lessons when the child's attention is at its end. Some students can relax and show their full potential when using the iPad." With regard to perceived benefits, issues related to instruction and planning were also commonly reported. Responses to the open-ended survey item noted the extent to which iPads could be customized to meet the needs of each child, the portability of the iPad and the capacity of the device to include a comprehensive array of activities. One special education teacher assistant wrote, "All needs in one tablet -- no pencils, paper etc req'd." Although least likely to be mentioned, student skill development was noted in seven separate responses including perception that the iPad was: 1) a powerful communicate aid, 2) well-suited to children with fine motor limitations, and 3) generally useful for instruction in foundational literacy and mathematics skills. In response to the survey item querying perception of iPad benefits, a special education teacher wrote: "Learning, 
learning, learning. Encourage language, fine motors skills, hand eye co-ordination, number recognition, letters, words - all things educational and fun."

Table 3. Teacher/Assistant Response to the Survey Item What do you see as the benefits of iPads for children in school?

\begin{tabular}{|c|c|}
\hline Category and Theme & Times Mentioned \\
\hline Student Motivation & $\mathbf{1 4}$ \\
\hline Enjoyable and engaging & 8 \\
\hline Attention and concentration & 3 \\
\hline Interactive & 3 \\
\hline Instruction and Planning & $\mathbf{9}$ \\
\hline Customizable & 5 \\
\hline Transportable & 2 \\
\hline Comprehensive activities & 2 \\
\hline Student Skill Development & $\mathbf{7}$ \\
\hline Communication skills & 3 \\
\hline Fine motor development & 2 \\
\hline Learning and achievement & 2 \\
\hline
\end{tabular}

Table 4 provides a summary of special education teacher and teacher assistant comments with regard to perceived problems using iPads with elementary school children with special needs. Overwhelmingly, identified challenges revolved around hardware, most notably the limited number of iPads available at school. A special education teacher assistant wrote: "We currently have two in a classroom of seven (a pretty good ratio most would think), but two of our students could benefit from having as a full time communication tool to travel with them from home to school and out to the playground." Teaching issues were also commonly noted by respondents including the perception that the tablets may not be used in the most instructionally effective manner. A special education teacher assistant wrote: "So many apps, limited time to explore and identify suitable ones for the classroom." In only two cases were problems associated with the children mentioned including that the iPad may actually increase social isolation because it is a solitary experience. A special education teacher assistant wrote: "Trying to limit time spent and moving on to another activity is sometimes difficult." A special education teacher wrote: "Students get addicted to iPads."

\section{Discussion of Survey Results and Implications for Instructional Practice}

As summarized in Table 1, participating teachers and assistants engaged in Internet use with the exception of playing online games, which is normative for females (Johnson, 2011).

Generalization of the survey results, consequently, is limited to special education teachers and teacher assistants who are likewise comfortable with digital technologies. That is, the generally positive evaluation of iPad use with students with special learning needs is based upon a level of teacher/assistant ease and familiarity with emerging technologies. Clearly, teachers/assistants who are less technologically capable may have very different perceptions than those who responded to the current survey. Nonetheless, the sample of teachers and assistants who completed the survey appeared relatively typical of those in many special education classrooms 
and, in this regard, findings may be generalized to many educational contexts for elementary school children with special needs.

Table 4. Teacher/Assistant Response to the Survey Item What do you see as the problems with iPads for children in school?

\begin{tabular}{|c|c|}
\hline Category and Theme & Times Mentioned \\
\hline Hardware Access and Maintenance & $\mathbf{1 2}$ \\
\hline More iPads required at school & 5 \\
\hline iPads required at home & 2 \\
\hline iPads may be damaged by children & 2 \\
\hline iPads are expensive & 2 \\
\hline Upgrades and maintenance of iPads & 1 \\
\hline Teachers and Teaching & $\mathbf{6}$ \\
\hline Effective instructional use of iPads & 4 \\
\hline Teacher acceptance of iPads as instructional tools & 1 \\
\hline Teacher training in best practices with iPads & 1 \\
\hline Student Skill Development & $\mathbf{3}$ \\
\hline Children may become dependent on iPads & 2 \\
\hline iPads may increase child's social isolation & 1 \\
\hline
\end{tabular}

In general, teachers and assistants were extremely positive about the utility of iPads for elementary school children with special needs. While all children reportedly responded favourably to tablet computers, some comments might be interpreted as suggesting that some children responded even more favourably than others (e.g., boys and children with autism). It is not clear, however, if such teacher/assistant comments imply a relative, rather than absolute, positive student response. That is, perhaps some children generally do not respond positively to learning activities and thus favourable responses to iPads were viewed as extremely positive. Two respondents suggested that children with cognitive limitations did not respond as favourably to iPad use in school as children with other types of special needs. It may be that the specific applications used in the Education Support Centre or features of the actual device (e.g., small screen and touch screen) are not equally appropriate for all types of students. Indeed, individuals with developmental disabilities have been excluded from the benefits of the digital revolution (Ignagni \& Abbas, 2008). Subsequent research and practice may identify the most effective use of specific hardware (e.g., devices) and software (e.g., iPad applications) for children with various differences in development.

According to responding special education teachers and teacher assistants, the iPads targeted the core curriculum areas of literacy and mathematics (Table 2). With respect to the perceived benefits, however, student academic skill development was the least likely to be mentioned (Table 3). Student motivation and engagement was the most common theme to emerge from responses to the survey item querying perceived benefits. Ten of the twelve teachers/assistants who responded to the survey claimed that they had not encountered a single student who did not enjoy using an iPad in school. The novelty effect has been used to explain increased student motivation associated with emerging technologies (Taormino, 2011). While new toys are often preferred over old toys, the characteristics of digital technologies, generally, and tablet computers, specifically, may provide such extreme variation (e.g., new apps and complex apps) 
that students could benefit from the novelty effect for extended periods of time. As Papagiannis (2010) suggested:

The novelty effect, or wonderment, does not necessarily wear off as the technology develops and becomes more established. The effect is not created by the technology itself but by the content created for it. As the technology develops further, content creators will (should) continue pushing the boundaries and create novel, compelling content that creates wonderment and curiosity. (Paragraph 2)

In addition to student engagement in the processes of learning, responding special education teachers and teacher assistants also frequently noted the convenience of the iPad as an instructional tool. Indeed, many early instructional applications of computer technology focused on student management and record keeping (Watson \& Watson, 2007). Tablet computers, however, because they are used by students, do not support teacher record keeping in the same ways as course management systems (e.g., Blackboard). Nonetheless, teachers/assistants frequently commented on the degree to which iPads were customizable, transportable and comprehensive in collection of various applications. In this regard, tablet computers appear to have the potential to be an essential aspect of individual program plans. Teaching tasks might soon include downloading and organizing specific applications on specific children's tablets. Professional development might likewise include examination and evaluation of various tablet applications in relation to specific student needs and capabilities. While teachers/assistants rarely reported observations of student skill development as the result of iPad use, enhanced student motivation and ease of individualizing instruction are likely to result in improved student competencies. Special education teacher and teacher assistant responses to the survey item that queried iPad benefits were remarkably similar to those expressed by teachers when computers were first introduced into special education classrooms, that is, that computers increased student engagement and teacher convenience (Ludlow, 2001). But quickly, the benefits of computers for children with learning challenges became apparent.

Special education teachers and teacher assistants identified iPad limitations which were remarkably similar to the reservations expressed by teachers to the educational introduction of any emerging technologies, -- that is, cost of hardware and lack of teacher skills and understanding (Wang \& Reeves, 2003). As one participating special education teacher wrote: "Government needs to review application downloading to allow broader licences otherwise becomes too expensive and limiting also." No participating special education teacher or teacher assistant identified lack of supporting research as problem with iPads. Daily use of tablet computers with children with special needs may have established for respondents the value of iPads in promoting the learning and development of exceptional students. Nonetheless, as Taormino (2012) observed, "The adoption of iPads in schools is something of a curiosity. How a tablet device contributes to learning over other delivery devices (PC, laptop, etc.) is still an open question" (paragraph 1). It may be, however, that computers of various sizes (e.g., desktop and tablet), with various input devices (e.g., key board and touch screen), will be available to special education teachers and their students. That is, tablet computers may not be alternate tools; they may be additional tools. 


\section{Limitations and Further Research}

A notable limitation of the current investigation is the narrow and small sample of special education teachers and teacher assistants. All respondent were drawn from one school. Caution must be exercised in generalizing findings to other contexts and under different conditions. Additionally, $80 \%$ of those invited to participate actually completed the survey. It is likely that those who chose to complete the survey differed from those who did not complete the survey. The participating teachers and teacher assistants provided self-report data; no direct observations occurred. An enduring criticism of self-report measures is the potential of misrepresentation particularly to present oneself in a positive manner (Kreuter, Presser, \& Tourangeau, 2008). Finally, student learning outcomes are more important than teacher perceptions and opinions, although the two are clearly related. Results of the current investigation cannot address the effect of tablet computer use on student academic achievement, arguably the most important determination.

Subsequent research may establish the extent to which results of the current investigation can be generalised to students who learn under different conditions (e.g., in different countries). Different mechanisms of collecting information may reveal the extent of influence of research methods on research findings (Johnson, 2008). Subsequent research may apply methods that attempt to establish the effectiveness of tablet computers on student learning (Johnson \& Howell, 2006). The required research design would randomly assign children to one of two conditions: use of tablet computers or no use of tablet computer. Such a study may be difficult to execute since parents may insist on one condition over the other thereby negating the required random assignment. Furthermore, it may be impossible to ensure no tablet computer use for some children who may use iPads outside of the school environment. Such limitations render teacher opinion, because it is possible and also because it is practice-based, of particular value.

\section{References}

Computers Desktop Encyclopaedia. (2012). Definition of: Tablet computer. Retrieved from http://www.pcmag.com/encyclopedia term/0,2542,t=tablet+computer\&i $=52520,00$.asp

Department of Education and Early Childhood Development. (2010). iPads in special education: Suggested applications and activities. Melbourne, Victoria, Australia; Communications Division for Student Wellbeing.

Dixon, D. (2011, October 11). School matters: The Future of apps in the classroom. The ASHA Leader. Retrieved from http://www.asha.org/Publications/leader/2011/111011/SchoolMatters--The-Future-of-Apps-in-the-Classroom.htm

Dunn, J, (2012, February). The 200 best special education apps. Edudemic [blog]. Retrieved from http://edudemic.com/2012/02/special-ed-apps 
Ellis, S. (2011). Teaching the future: How iPads are being used to engage learners with special needs. Screen Education, 63, 60-64. Retrieved from http://search.informit.com.au/documentSummary; $\mathrm{dn}=445341941466124 ;$ res=IELHSS

Grezlak, M. (2011, January 18). Some facts \& myths regarding classroom iPads [blog]. Retrieved from http://teachpaperless.blogspot.com/2011/01/some-facts-mythsregardingclassroom.html

Harrison, D. (2010). Ushering iPads into the classroom. T.H.E. Journal. Retrieved from http://thejournal.com/Articles/2010/10/13/Ushering-iPad-Into-the-Classroom.aspx?Page=1

Ignagni, E., \& Abbas, J. (2008). Media and messages: Exploring old and new worlds of developmental disability and the media. Journal on Developmental Disabilities, 14(3), 8692.

Jackson, S. (2011, April 25). iPads in the classroom: Integration matters [Blog]. Retrieved from http://spotlight.macfound.org/blog/entry/ipads-in-the-classroomintegration-matters/

Johnson, G. M. (2008). The effectiveness of distance education vs. classroom instruction: A summary of Bernard's meta-analysis with implications for practice. International Journal of Instructional Media, 35, 137-144.

Johnson, G. M. (2011). Internet activities and developmental predictors: Gender differences among digital natives. Journal of Interactive Online Learning, 10(2), 64-76.

Johnson, G. M. (2013). Tactile input features of hardware: Cognitive processing in relation to digital device. International Journal of Research and Reviews in Applied Sciences, 41(2), 464-469. Retrieved from http://www.arpapress.com/ijrras/Volume14issue2.aspx

Johnson, G. M., \& Howell, A. J. (2006). The impact of Internet learning technology: Experimental methods of determination. In B. L. Mann (Ed.), Selected styles in web-based educational research (pp. 282-301). Hershey, PA: Idea Group Publishing.

Kreuter, F., Presser, S., \& Tourangeau, R. (2008). Social desirability bias in CATI, IVR, and web surveys: The effects of mode and question sensitivity. Public Opinion Quarterly, 72(5), 847-865.

Learmonth, M. (2010, June). How the iPad became child's play-and learning tool. Advertising Age, 81(23), 4. Retrieved from ABI/INFORM Global. (Document ID: 2055148991).

Ludlow, B. L. (2001). Technology and teacher education in special education: Disaster or deliverance? Teacher Education and Special Education, 24(2), 143-163. doi: 10.1177/088840640102400209

McCrea, B. (2010, January). Measuring the iPad's potential for education. T.H.E. Journal. Retrieved from http://thejournal.com/articles/2010/01/27/measuring-the-ipads-potentialfor-education.aspx 
Namahoe, K. (2012, March). Students with ADHD get help from iPad app. T.H.E. Journal. Retrieved from http://thejournal.com/articles/2012/03/02/adhd-students-get-help-fromipad-app.aspx

Papagiannis, H. (2010, November). Notes in the cloud [blog]. Retrieved from http://notes-in-thecloud.blogspot.com.au/2010/11/ar-novelty-effect.html

Rock, M. (2011, December 1). Tablets may benefit children with autism. Tabletedia. Retrieved from http://www.tabletedia.com/news/4524.html

Tablet Computer News. (2011, February 2). iPad helps special needs children. Retrieved from http://tabletcomputer.org/apple-ipad/ipad-helps-special-children

Taormino, M. (2011, May). iPad: Valuable tool or technolust? Follow the carpenter's rule! Las Vegas Technology in Education Examiner. Retrieved from http://www.examiner.com/technology-education-in-las-vegas/ipad-valuable-tool-ortechnolust-follow-the-carpenter-s-rule\#ixzz1 qrcLLozH

Taormino, M. (2012, March). Ipad 3: Evolutionary or revolutionary? Las Vegas Technology in Education Examiner. Retrieved from http://www.examiner.com/technology-education-inlas-vegas/ipad-3-evolutionary-but-not-revolutionary?CID=obinsite

Valentino-Devries, J. (2010, October 13). Using the iPad to connect: Parents, therapists use Apple tablet to communicate with special needs kids. The Wall Street Journal. Dow Jones and Company.

Wang, F., \& Reeves, T. C. (2003). Why do teachers need to use technology in their classrooms? Issues, problems and solutions. Computers in the Schools, 20(4), 49-65. doi: 10.1300/J025v20n04_05

Watson, W. R., \& Watson, S. L. (2007). An Argument for Clarity: What are Learning Management Systems, What are They Not, and What Should They Become? TechTrends, 51(2), 28-34.

\section{Author}

Dr. Genevieve Marie Johnson is a senior lecturer at the School of Education at Curtin University in Western Australia. Her research agenda includes theoretical, empirical, and practical understanding of digital technologies and human learning and development. For the details of Genevieve's professional contributions, visit her page at http://members.shaw.ca/gen.johnson/ Email: g.johnson@curtin.edu.au.

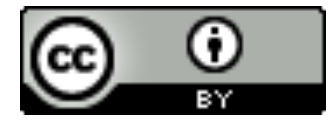

This work is licensed under a Creative Commons Attribution 3.0 License. 